\title{
ZUR ANGELSAECHSISCHEN GENESIS.
}

Die sogen. Cädmonische Genesis ist, abgesehen von der von Sievers so gründlich untersuchten interpolierten partie, noch nicht gegenstand einer besonderen eingehenden literargeschichtlichen behandlung gewesen, denn was Götzinger in seinem bekannten schriftchen darüber äussert, will wenig bedeuten, wenn er auch einzelne richtige bemerkungen macht. Beim fortschreiten meiner Literaturgeschichte des Mittelalters sah ich mich daћer genötigt, die arbeit selbst zu unternehmen und um zu einem sicheren urteil uber die angelsächsische dichtung zu gelangen, durfte ich nicht die zeitraubende mïhe scheuen, dieselbe schritt für schritt mit der bibel, selbstverständlich der Vulgata, zu vergleichen. Natürlich war von der oben erwähnten interpolation abzusehen. Aber auch die derselben vorausgehende partie fasse ich in dem vorliegenden aufsatze nicht in's auge, denn so weit ihr uberhaupt die bibel zu grunde liegt, erscheint die behandlung derselben doch etwas eine andere, so dass man wol daran denken kann, für diese erste partie einen besonderen verfasser anzunehmen. Auf diese frage aber genaner einzugehen habe ich hier nicht die absicht. Ich beschränke mich hier also auf die der interpolation folgende partie, von vers 852 bis zum schlusse der dichtung. Sie erstreckt sich von cap. 3, v. 8 bis cap. 22 , v. 13 des ersten buches Mose.

Um die art, wie der verfasser seine vorlage behandelt hat, zu zeigen, unterscheide ich zunächst zusätze und weglassungen.

Die zusätze sind einmal zum zwecke der erklärung des biblischen berichts, dann insbesondere zur motivierung der berichteten handlungen gemacht. Betrachten wir zunächst den ersten fall. So wird v. 908, wo Gott die schlange verflucht, diese als fềeleás bezeichnet, um zu erklären, dass sie auf ihrer 
brust gebt. So wird die antwort Kain's auf Gottes frage, wo Abel sei: Nescio. Num custos fratri. mei sum ego? (c. 4, v. 9) widergegebeu: Ne can ic Abeles ôr ne fôre, hleómấges sî̀: ne ic hyrde wces brôঠer mînes (v. 1006 ff.) - um das durch hyrde übertragene custos zu erklären. Cap. 16, v. 5 beginnt Sara, uber Hagar erbittert, ihre zornige rede gegen Abraham: Inique agis contra me, ohne diese worte direct zu begründen: unser dichter erklärt sie mit den worten: pafodest pugena, pcet me beówmennen - - drêhte dôgora gehwam dôedum and wordum v. 2246. Cap. 20, v. 9 macht der von Gott bedrohte Abimelech dem Abraham den vorwurf, dass er ihn in diese lage gebracht, indem er sagt: quae non debuisli facere, fecisti nobis. Was Abimelech meint, ergibt sich aus dem vorher erzählten; der angelsächs. dichter aber hält es trotzdem für nötig, den Abimelech selbst den vorwurf ausdrücklich darlegen zu lassen v. $2679 \mathrm{ff}$., wobei dieser in seiner rede noch wesentlich verschärft wird. - Auch kleine veränderungen nimmt der verfasser zum zwecke der erklärung vor, so lässt er den Lamech sogleich den 'mann', den er tötete (c. 4, v. 23), als den Kain bezeichnen (v. 1095); so gibt er die filiae hominum (c. 6, v. 2) durch frauen aus dem geschlechte Kain's wieder, indem er die flii Dei aus dem geschlechte Seth's sein lässt (v. 1245) ${ }^{1}$; so überträgt er die fontes abyssi in der erzählung von der sindflut (c.7, v. 12) durch willeburnan - - of $\hat{e} d r a$ gehwôcre (v. 1373); so ersetzt er in der rede des Abraham zu Lot das fratres enim sumus (c. 13, v. 8) durch eine genauere angabe des verwantschaftsverhältnisses: Ic eom fadera pîn sibgebyrdum, b̂̂ mîn suhterga (v. 1900 f.); so scheint es, dass er in der an Abimelech gerichteten rede Gottes (c. 20, v. 7) das quia propheta est (sc. Abraham) ersetzt durch die erklärenden worte: he is - gleán, mag self [wið god] sprecan, geseon sweglcyning (v. 2657 f.).

Ebenso finden sich manche zusätze, um eine von der bibel berichtete handlung zu motivieren. So wird v. $1431 \mathrm{ff}$. Noah's wunsch zu landen, angeführt als grund, warum er die vögel aussendet. Um die wanderung der nachkommen Noah's nach dem lande Sennaar (c. 11, v. 1) zu motivieren, lässt sie der dichter ein 'geräumigeres land' suchen (vers 1651). Die

1 So erklärt auch Beda (In Pentat. comment. Genes. cap. 8) diese ausdrücke. 
teilnahme der bundesgenossen Abraham's an der befreiung Lot's (c. 14, v. 15) wird durch eine bitte Abraham's begründet (v. 2025); der segensspruch Melchisedech's (c. 14, v. 18) durch Abraham's sieg ( nahen, stadt Segor statt nach dem berge fliehen dürfe (c. 19, v. 18), durch die begleitung seiner frauen, die keinen so weiten weg zu fusse machen können (v. $2512 \mathrm{ff}$.).

Es gibt aber noch andere arten von zusätzen, und zwar solche, die für den angelsächsischen dichter recht bezeichnend sind. So ergreift er gerne die gelegenheit, im detail auszumalen, was in der bibel nur mit wenigen strichen gezeichnet oder auch blos angedeutet ist, und es sind dies nicht allein natur-, sondern auch characterschilderungen, landschaftsbilder und historische gemälde, die selbst zu längeren- episoden werden. Da zeigt sich uns denn auch die poetische begabung des verfassers. Durch wie manche hübsche einzelne züge ist die sindflut veranschaulicht; und dem bilde ist noch ein besonderer reiz verliehen durch das lebhafte interesse, das es in seiner ausfuhrung an der arche und ibren bewohnern erweckt, wie in der stelle: Siððan wîde râd wolcnum under ofer holmes hrincg hof sêleste u. s. w. (v. 1392 ff.). Wie reizend ausgeführt ist die kleine episode von dem ausflug der zweiten taube, worin der dichter erzählt, wie dieselbe den ölzweig gewann (v. 1464 ff.). So wird ferner der anbau des landes durch Noah, den nur eine zeile in der bibel anzeigt, in sieben versen geschildert (v. $1555 \mathrm{ff}$ ); ebenso darauf ausfuhrlich die trunkenheit Noah's und seine verspottung. Besonders begierig aber nimmt der Angelsachse die gelegenheit zu einer kampfesschilderung wahr, welche ihm der cap. 14 berichtete krieg des königs der Elamiter mit dem von Sodom bietet; werden hier in der bibel nur die localitäten und das resultat näher angezeigt, so gibt unser dichter (v. 1982 ff.) ein lebendiges gemälde der schlacht, allerdings einer, wie sie die Angelsachsen lieferten, mit dem ganzen lärm der auf helm und lindenschilde dröhnenden speere und schwerter; auch 'fehlt nicht der schwarze Odinsvogel, der leichengierige rabe. So wird auch, um von kleineren zusätzen dieser art abzusehen, der brand von Sodom und seiner umgegend mit kräftigem pinsel gemalt ( $\nabla .2545 \mathrm{ff}$.). Aber auch psychische vorgänge werden treffend geschildert, so der zorn des Kain, wie er sich aus den 
beklemmungen des neids entwickelt: poet woes torn were hefig at heortan: hygewcelmas teáh beorne on breóstum blâtende nî̀, yrre for $\hat{\alpha} f s t u m$ (v. $979 \mathrm{ff}$.), wo die bibel (c. 4, v. 5) nichts als die worte: iratusque est Cain vehementer bot. Noch sei erwähnt wie unser dichter bei der blossen erwähnung der verheiratung Abraham's in der bibel (c. 11, v. 29) ein bild der Sara entwirft, indem er sie nicht nur lieblich und edel nennt, sondern sie auch in ächt angelsächsischer weise als gute hausfrau bezeichnet in den worten: Hie pa wintra fela woruld bryttedon, sinc oetsomne sibbe heóldon geâra mengeo (v. 1724 ff.).

Schon die art dieser zusätze, noch mehr ihre ausführung, zeigt, wie bereits angedeutet, dass der verfasser die bibel nicht blos in angelsächsischer sprache, sondern auch im angelsächsischen geiste bearbeitete. $\mathrm{Er}$ lässt die von ihm erzählten handlungen gleichsam in seinem volke vor sich gehen, indem er die einrichtungen, sitten und gebräuche, tugenden und fehler desselben, ja selbst die natur seines landes, so weit dies möglich ist, in die zeit und scene der biblischen erzählung tiberträgt. Da werden nicht blos die ämter und würden der Angelsachsen den biblischen substituiert (s. v. 1870 und 2178), nicht blos im geschlechtsregister Adam's ein stammhalter wie Cainan als aldordêma, neard and wisa bezeichnet (v.1156 f.), was sich wol rechtfertigen liesse, sondern ein anderer dort, Geared, geradezu wie ein angelsächsischer fürst characterisiert mit den worten: gumum gold brittade (v. 1181). Selbstverständlich sind dem Angelsachsen die patriarchen, wie Abraham und Lot, von adeliger geburt (v. 1716, vgl. auch v. 2771). Auch hier besteht der reichtum in ringen, gewundenem gold und kleinodien: Lot vergisst sie nicht mitzunehmen, als er nach Sodom zieht (v. 1930 f.), obgleich in der bibel (c. 13, v. 12) nichts weiter gesagt ist, als dass er nunmehr in Sodom wohnte. - So wird das geschrei, das von Sodom zu Gott'kam (c. 18, v. 21), fur ealogâlra gylp erklärt (v. 2408). - So wird ferner der abschluss eines bündnisses, das Abimelech von Abraham erbittet, in angelsächsischer form gegeben ( $v$. $2828 \mathrm{ff}$.). Des verfassers nationalität offenbart sich auch recht in seiner kenntniss des seewesens und seiner liebe zum meere: die erstere zeigt er namentlich bei der schilderung der arche, die er durch einen ton, der im wasser immer härter wird, verkitten lässt (v. 1322), die andere durch erwähnung des meeres bei seinen 
naturschilderungen, so z. b. schimmern - in der schönen ausführung der stelle, wo Gott Abraham auf den sternenhimmel blicken heisst, die vermebrung seines geschlechtes zu erfabren (c. 15, v. 5) - die sterne über der breiten meeresbrandung (v. 2192), so verhüllt die nacht bei ihrem einbruch in Sodom die lagustreámas, sês and sîd land (v. 2449 ff., c. 19, v. 4).

Die persönlichkeit des dichters tritt aber auch direct hervor, indem er es nicht unterlässt, an wichtigen stellen seine teilnahme an dem erzählten zu bezeizen. So ruft er nach der verweisung der erzältern aus dem paradiese aus: Wir hörten nun, wo unser schlimmes unheil erstand und das weltelend (v. $939 \mathrm{f}$ ); und der mord Kain's veranlasst ihn zur klage über den sündenfall, dessen folge jener mord war, der, ein steckling, weite zweige trieb, aus denen breite blätter jeder bosheit sprossten - und noch zu des dichters zeit (v. 987 ff.). So rühmt er Abraham ob des sieges, durch welchen er Lot befreite (v. 2092). Einen solchen subjectiven character haben noch andere stellen, wie die schöne, worin der dichter sagt, dass nach der vertreibung aus dem paradiese doch den erzältern noch der trost des gestirnten himmels und der fruchtbaren erde geblieben wäre (v. 952 ff.). Beachtenswert ist, dass ganz im gegenteil Avitus in seiner dichtung hervorhebt, wie hässlich die erde im vergleich mit dem verlorenen paradiese dem ersten menschenpaare erschienen sei (1. III, v. 201 ff.).

Endlich finden sich noch eine anzahl zusätze, die besonsondere theologische studien des verfassers verraten. Auf eine stelle, v. $154 \mathrm{i} \mathrm{f.,} \mathrm{hat} \mathrm{schon} \mathrm{Götzinger} \mathrm{(s.} \mathrm{18)} \mathrm{aufmerksam} \mathrm{ge-}$ macht; dort werden die namen der vier weiber der arche gegeben.' Dazu kommen noch folgende stellen: In dem geschlechtsregister. Genes. c. 5 wird das scheiden Enoch's durch die worte angezeigt: et non apparuit quia tulit eum Deus (v. 24); unser dichter berichtet ausführlich seine himmelfahrt und bemerkt dabei, er wäre lebend mit dem könig der engel aus diesem vergänglichen leben gefahren: on pâm gearwum, be his gâst onfêng, ểr hine tô monnum môdor brohte (v. 1212); soll dies

1 Nicht der vier schwiegertöchter, wie Götzinger sagt, sondern der drei und des weibes Noah's. - Eine andere stelle wird von Götzinger irrtïmlich als abweichung vom biblischen texte angeführt; G. hat hier nicht das ags. original, sondern die übersetzung Grein's vor augen gehabt, die allein die falsche zahlenangabe enthält. 
nur heissen: im mutterleibe? - Der rabe kehrt zur arche nicht zurück, weil er eine leiche zum frasse findet (v. 1447); dasselbe motiv findet sich auch bei Avitus IV, v. 566. - Genes. c. 9, v. 6 heisst es: Quicunque effuderit humanum sanguinem, funditur sanguis illius: ad imaginem quippe Dei factus est homo. Unser dichter gibt den letzteren satz wörtlich wieder, fügt dann aber noch hinzu: aelc hafað mâgwlite metodes and engla, pâra be healdan wile hâlige peámas (v. $1530 \mathrm{f}$.). - V. 1648 wird der name Ebrêi von Eber hergeleitet. - V. 1661 ff. wird der turm von Babel nicht blos zum ruhme, sondern auch zur erinnerung an den aufenthalt in diesem lande errichtet. V. 1767 wird Hara (Carran) als Assyrien, oder als in Assyrien bezeichnet (vgl. Gen. c. 11, v. 31 und c. 12 init.). - Lot's frau steht als salzsäule noch immer da ( $\nabla .2565$ ff.). Dasselbe wird u. a. auch in dem gedichte 'De Sodoma' (aus dem 4. jahrh.) erzählt (v. $121 \mathrm{ff}$.). Dies sind die wichtigsten stellen.

Auch die weglassungen characterisieren den dichter und sein werk. Sie haben verschiedene gründe. Einzelne stellen scheinen mir von dem dichter übergangen zu sein, wèil er sie selbst nicht verstanden; so c. 3, v. 22, wo Gott sagt: Ecce Adam quasi unus ex nobis factus est u. s. w., oder c. 4, v. 1, wo Eva spricht: Possedi hominem per Deum, oder c.4, v.7. Weit mehr stellen aber sind weggelassen aus dem grunde, weil sie dem angelsächsischen leser auch in der bearbeitung unverständlich und uninteressant sein mussten. So alle erklärungen von namen - deren verständniss ja eine kenntniss des Hebräischen voraussetzte - wie von Noah (c. 5, v. 28), Babel (c. 11, v. 9), Segor (c. 19, v. 22), Bersabee (c. 21, v. 31), ähnlich auch c. 16, v. 13 ff.; die namensveränderungen von Abraham und Sara (c. 17, v.3 u.15). Auch das von Gott Abraham gebotene opfer der verschiedenen tiere und die sich daran reihende vision cap. 15, v. 8 musste einem Angelsachsen zu fremdartig erscheinen; so blieb die ganze stelle bis v. $18 \mathrm{weg}$. Ebenso wurden die 'azyma', welche Lot den engeln, seinen gästen, vorsetzt (c. 19, v. 3), als rein juidische sitte weggelassen. Auch den zu starken anthropomorphismus c. 8, v. 21, wo Gott den duft von Noah's opfer riecht, durfte wol als zu unchristlich der dichter nicht seinen lesern bieten. Aus demselhen grunde blieb gewiss die stelle weg, worin Abraham, gegen Abimelech sich entschuldigend, sagt, dass Sara wirklich seine schwester, nämlich seine stief- 
schwester sei (c. 20, v. 12). Auch wird dem dichter irreligiös erschienen sein, dass Sara nach der geburt Isaac's sagt, Gott habe sie zum gelächter gemacht (c. 21, v. 6), und so ubergieng er dies lieber. $\mathrm{Ob}$ auch ein religiöses motiv den dichter bei der weglassung der intervention Abraham's für Sodom (c. 18, v. 22 ff.) bestimmte, sei dahin gestellt. - Offenbar aus achtung vor Abraham lässt er die vorwurfsvolle rede Pharao's, da sie allerdings wol begründet war, weg (c. 12, v. 18). - Hier und da finden sich auch kürzungen um widerholungen zu vermeiden, wie im c. 9. Endlich hat der verfasser auch aus ästhetischer rücksicht einzelne partieen als ganz uninteressant weggelassen, wie blosse namenangaben, die ausserdem der alliterierenden dichtung grosse schwierigkeiten bereiten mussten, so die namen von königen und völkern bei den kriegen der Elamiten gegèn Sodom c. 14; so die aufzählung der generationen der söhne Noah's c. 10 und 11; auch die angabe eines datums wird einmal übergangen, wie des aufhörens der sindflut (c. 8 , v. 13 f.).

So sehen wir, wie der dichter mit verständiger überlegung sich überall bemüht, den alttestamentlichen stoff dem nationalen und christlichen bewusstsein seines volkes entsprechend zu behandeln und so ihm sympathisch und auch im einzelnen verständlich zu machen; zugleich sucht er durch die ausführung dem stoffe einen poetischen reiz zu verleihen, ohne etwas wesentliches aufzuopfern. Dieser teil der 'Genesis' hat keinen so rhetorischen character, wie er in der angelsächsischen dichtung häufig begegnet, sind doch hier der reden weniger als in der biblischen vorlage, indem der inhalt mancher von diesen nur durch den dichter erzählt wird ${ }^{1}$; freilich zeigt dieser abschnitt auch kein so reiches colorit als die beiden anderen oder der Exodus, aber er hält sich auch frei von schwulst in seiner verhältnissmässig einfachen ausdrucksweise, die jedoch der kunst nicht entbehrt. Letzteres gibt recht zu erkennen das geschlechtsregister von Adam bis Noah, welches der verfasser nicht weglassen zu dürfen glaubte, in der grossen mannigfaltigkeit der ausdrücke für leben und sterben. Da zeigt sich der gelehrt gebildete dichter, welchen die ganze

1 So vgl. c. 11 , v. 7 f. und Gen. v. 1684 f., c. 13 , v. 14 und Gen. v. 1946 ff., c. 19 , v. 1 und Gen. v. 2432. 
arbeit verrät. Dass dieser teil der Genesis nicht von Cädmon sein kann, ist für jeden, der das gedicht gründlich studiert hat, indem er es mit der bibel verglich, selbstverständlich; denn wenn man auch von allem andern, was gegen eine solche annahme spricht und in der vorstehenden untersuchung sich niedergelegt findet, absieht, so zeigen gar manche stellen offenbar, dass der dichter bei der abfassung seines werkes die bibel vor augen hatte, selbst sie gelesen und studiert hat, er hätte sonst kürzungen und umstellungen, wie sie sich hier und da finden, nicht in der art wie es geschehen vornehmen können. ${ }^{1}$

Dies darzulegen wäre zu weitläufig und ist auch unnötig. Denn wenn man die mitteilung Beda's uber Cädmon (Hist. eccles. l. IV, c. 24) sorgfältig liest und unbefangen erwägt, kann man keinen zweifel dartiber hegen, dass weder der hier betrachtete, noch ein anderer abschnitt der Genesis von Cädmon verfasst ist. Wie sich aus der nachricht Beda's ergibt, waren seine frommen carmina vielmehr hymnusartige gedichte, die im gesang vorgetragen wurden, also gedichte ganz anderer art als die Genesis.

Stellen wir einmal die einzelnen punkte der Beda'schen überlieferung, welche diesen character der dichtung Cädmon's bekunden, kurz zusammen.

Der äussere anlass, welcher den frommen, aber ganz ungebildeten klosterknecht zum dichter machte, war bekanntlich die beschämung, die er darüber empfand, dass er bei dem mit seinen genossen eingenounmenen mahle, wenn die harfe herumgieng, nicht auch etwas singen konnte. Religiöse inspiration kommt ihm zu hülfe. Er verfasst also ein lied, wie er es vortragen konnte, wenn ihm wider im kreise der genossen die aufforderung wurde.

Im kloster zweifelt man an der begabung Cädmon's und unterwirft ihn einer prufung. Exponebantque illi, heisst es da weiter, quendam sacrae historiae sive doctrinae sermonem,

1 Auch versteht er zwischen den zeilen zu lesen. Wenn er v. 1507 bei gelegenheit des opfers Noah's sagt, dass dieser in seiner jugend durch gute taten die gnade, die ihm von Gott wurde, verdient hatte, so ist er zu dieser in der bibel fehlenden bemerkung durch c. 8, v. 21 geführt worden, wo es heisst: sensus et cogitatio humani cordis in malum prona sunt $a b$ adolescentia sua. Noah hatte eine ausnahme gemacht. 
praecipientes eum, si posset, hunc in modulationem carminis transferre. At ille suscepto negotio abiit, et mane rediens optimo carmine quod iubebatur compositum redidit. In der weise liess sich wol eine hymne, aber kein gedicht in der art der Genesis verfassen. Die worte exponebant und doctrinae sind wol zu beachten. Es wurde Cädmon ein bibeltext erklärt; nicht also eine stelle der bibel vorerzählt oder nur vorgelesen.

Cädmon wurde nun in das kloster aufgenommen und ihm die bibel gelehrt. Alles, was er durch hör en lernen konnte (quae audiendo discere poterat), rief er sich zurïck und verarbeitete es in sich, verwandelte es in ein liebliches gedicht und trug es in reizendem gesange (suaviusque resonando) seinen lehrern vor. So 'sang' er von der schöpfung der welt und von den meisten geschichten der heiligen schrift, von den schrecken des juingsten gerichts und von der herrlichkeit des paradieses, aber er machte auch mehrere gedichte von den woltaten und gerichten Gottes, und in allen diesen strebte er die menschen von der sünde abzuziehen und zu einem guten leben anzuregen. Der gegenstand dieser zuletzt erwähnten 'carmina' wirft auch ein licht auf die art seiner poetischen behandlung der biblischen stoffe. Cädmon wird ohne frage nur in einer form oder stilart der poesie gedichtet haben, also in derselben form von den woltaten und gerichten Gottes wie von der schöpfung der welt gesungen haben; und bei der behandlung des einen wie des andern themas verfolgte er eine didactische tendenz, sein frommer sinn war es ja, der ihn zum dichter machte: zu dieser hier von Beda ausgesprochenen didactischen tendenz passt vollkommen das doctrina in der oben citierten stelle, nicht minder die bemerkung Beda's im eingange des kapitels, dass durch Cädmon's gedichte viele zur verachtung des weltlichen lebens entflammt worden wären. ${ }^{1}$

Nach allen diesen einzelnen momenten der erzählung Beda's, der selbst sicher Cädmon's gedichte gekannt hat und uberbaupt gewiss ein ganz treuer berichterstatter hier, wie auch sonst in seinem werke, war, da er in seiner kindheit vielleicht noch ein zeitgenosse Cädmon's und dessen kloster nicht sehr fern von dem seinen lag (etwa 10 deutsche meilen) -

1 Ebenso auch der satz im eingange des berichts Beda's: quia carmina religioni et pietati apta facere solebat. 
nach allen diesen momenten war Cädmon's poesie eine didactisch-lyrische. Dafür spricht auch die grosse zahl der biblischen stotfe, die er nach Beda behandelt hat. Wenn endlich Beda aber noch bemerkt, dass nach Cädmon auch andere im volke der Angeln religiöse gedichte (religiosa poemata) zu machen versuchten, aber keiner ihm gleichkommen konnte, so braucht man hier nicht auch an hymnendichter zu denken. Religiöse gedichte konnten auch solche wie die Genesis genannt werden. Ihre wirkung, meint Beda nur, war eine weit geringere. ${ }^{1}$ Denn, fügt er hinzu, Cädmon war nicht von menschen in der sangeskunst unterrichtet, vom himmel empfieng er die gabe.

Die epochemachende bedeutung Cädmon's liegt aber darin, dass er zuerst in der volkssprache christliche stoffe behandelte; er verfuhr dabei als ein ungelehrter mann aus dem volke selbst wie ein volkssänger, wie der scop, der im Beówulf von der schöpfung singt: den stoff empfieng er wie jene durch mündliche überlieferung und bearbeitete ihn zum gesange, zum mündlichen vortrage. Indem er aber von haus aus unnationale, literarische, d. h. in büchern tiberlieferte, stoffe in der weise der volkssänger behandelte, zeigte $\mathrm{er}$, wie das fremde material dem genius der nation assimiliert werden konnte, und schlug so die brlicke zu einer kunstpoesie uberhaupt, die nach ihm eben mit der behandlung derselben religiös-christlichen stoffe beginnt.

LEIPZIG.

ADOLF EBERT.

.1 Es ist wol zu beachten, dass der satz, worin Beda von den nachfolgern Cädmon's spricht, sich unmittelbar an jenen anschliesst, worin er von der wirkung der carmina Cädmon's gesprochen. 